\title{
Inovação no sistema Judiciáriocom a adoção do Processo Judicial eletrônico em um Tribunal de Justiça brasileiro
}

\author{
Innovation in the Judiciary system with the adoption of the Electronic Judicial \\ Process in a brazilian Courthouse
}

\author{
Janaina Angelina Teixeira ${ }^{1}$ \\ Mariana Carolina Barbosa Rêgo²
}

\begin{abstract}
Resumo
O Judiciário brasileiro tem buscado alternativas que visam adesburocratização dos processos em prol da eficiência do serviço público, uma dessas alternativas é o sistema Processo Judicial Eletrônico - PJe, que permite o acompanhamento online da tramitação dos processos e a participação mais efetiva e transparente dos profissionais que dele fazem uso. Nesse contexto, o estudo em pauta tem como objetivo analisar a adoção e implementação do PJe, no Tribunal de Justiça do Distrito Federal - TJDFT, sob a percepção dos advogados. A pesquisa foi realizada por meio de entrevistas com 25 advogados que atuam neste Tribunal. Os resultados encontrados vão ao encontro da literatura de inovação no setor público e no Judiciário e com base na análise de conteúdo foram definidasseis categorias: adoção de inovações no Judiciário brasileiro, impactos procedimentais, oportunidades de melhoria sistema, impactos para o TJDFT, impactos para a celeridade e qualidade das decisões judiciais, estratégias para o desenvolvimento de competências e suporte ao sistema e desenvolvimento.Como principais resultados, os advogados percebem possíveis impactos positivos para o seu trabalho e para a celeridade da decisão judicial, enfatizando a redução de custos nas operações, porém o sistema ainda apresenta muitas oportunidades de melhoria, principalmente em relação ao acesso e funcionamento do PJe. De forma geral, os resultados indicaram que existe uma falta de integração entre o Judiciário e os advogados, bem como a falta generalização do sistema, no sentido de um sistema nacional único, uma vez que cada estado possui um sistema próprio com suas próprias regras. Esse distanciamento dificulta o desenvolvimento de um sistema que esteja alinhado com as necessidades do usuário e que os advogados tenham uma visão sistêmica da situação atual do Judiciário. Dessa forma, os resultados corroboram a necessidade de ampliação da adoção e difusão de inovações no Poder Judiciário e a relevância da comunicação e do envolvimento dos diversos atores no processo de implementação dessas inovações.
\end{abstract}

Palavras-chave: Inovação. Adoção de Tecnologia. Setor Público. Poder Judiciário. Processo Judicial eletrônico

\begin{abstract}
The Brazilian Judiciary has sought alternatives to reduce the bureaucracy of lawsuitsand increase public service efficiency. One of these alternatives is the Electronic Judicial Process (PJe) system, which allows online follow-up of the cases and a more effective and transparent participation of professionals. In this context, the study aims to analyse the adoption and implementation of the Electronic Judicial Process - PJe, in the Court of Justice of the Federal District - TJDFT, under the perception of lawyers. The data was collected through interviews with 25 lawyers that work in this Court. The results collaborate with the theories of innovation in the public sector and in the Judiciary. For the analysis and the discussion of the results, based on content analysis, six categories were defined:innovations in the Brazilian Judiciary System, procedural impacts of the technology, opportunities for technology improvement, impacts of the innovation for the TJDFT and impact on the speed and quality of judicial decisions. The main results are that the lawyers see the potential impacts of the technology to their work and to the speed of the judicial decisions, emphasizing the reduction of costs in operations, but there is still need for improvement. In general, the results indicate that there is a lack of integration between the layers and the Courthouse, as well as the generalization of the system in a single national system, since each state has its own system with its own rules. This detachment hinders the development of an information technology that is aligned with the user's needs and that the lawyers have a systemic view of the Judiciary system. The results support the need to expand the adoption and diffusion of innovations in the BrazilianJudiciary and the need of communication and involvement of various actors in the change process and in the implementation of these innovations.
\end{abstract}

Keywords: Innovation. Technology Adoption.Public Sector.Judiciary. Electronic Judicial Process

Mestre em Administração - PPGA - Universidade de Brasília. Brasil. Afiliação: Universidade de Brasilia. Lattes: http://lattes.cnpq. br/5805967434280373 Email: janaina.angelina@gmail.com

2 Doutoranda em Administração - PPGA - Universidade de Brasília. Brasil. Afiliação: Universidade de Brasília. Lattes: http://lattes.cnpq. br/1525030197427442 Email: marianaacarolina@gmail.com 


\section{Introdução}

Inovação é o desenvolvimento ou adoção de um novo ou melhor produto ou serviço, podendo ser concebida em quatro perspectivas: processo, método de marketing, forma organizacional e produto, bem ou serviço (Oecd, 2005). A inovação é moldada pelas características gerais do ambiente competitivo, na medida em que esses recursos são características estruturais e funcionais gerais dos mercados de serviços (Hauknes, 1998).

Um aspecto evidente da sociedade moderna, que muitas vezes é negligenciado pelas pesquisas, é o setor público. Geralmente, as atividades públicas são vistas como legais e regulatórias, produtoras de bens complementares, financiadoras da inovação no setor privado, ou ainda como clientes dessas inovações. Apesar deo setor público poder ser um protagonista nos processos de inovação (Koch \& Hauknes, 2005), barreiras materiais, estruturais e externas fazem com que a inovação ainda seja um desafio a ser ultrapassado por meio de passos lentos (Koch \& Hauknes, 2005). Essa carência de pesquisas sobre o fenômeno é realidade de muitos países (Koch \& Hauknes, 2005), tornando necessário o desenvolvimento de estudos empíricos sobre inovações na administração pública.

Quando se consideram pesquisas sobre inovações no Poder Judiciário, essa lacuna é ainda maior. Ainda que essa barreira venha sendo transposta e, nos últimos anos, tenha se percebido um aumento significativo das publicações na área, principalmente quanto a inovações organizacionais e gerenciais, tais como adoção e melhorias de técnicas de planejamento, inovações judiciais e tecnológicas (Sousa \& Guimarães, 2014), há um campo promissor para pesquisa sobre esse tema no setor.Nesse sentido, a abertura do Judiciário brasileiro às reformas e mudanças é importante para que se possa alcançar o protagonismo almejado no texto constitucional. Uma dessas mudanças está concentrada na promulgação da Lei 11.419/2006, que implementa inovações que favorecem a agilidade e eficiência no acompanhamento da tramitação dos processos judiciais (Brasil, 2006). No modelo de actuação da tecnologia, Fountain (2005) enfatiza que as estruturas organizacionais influenciam na transformação, desenvolvimento, implementação e uso da tecnologia. Assim, faz-se importante observar, além dos resultados nos processos organizacionais internos, a participação e a percepção de todos os envolvidos no processo de adoção de tecnologias, uma vez que influenciam o resultado final da tecnologia implementada.

Isto posto, este trabalho concentra-se no sistema Processo Judicial eletrônico - PJe, criado pelo Conselho Nacional de Justiça ( $\mathrm{CNJ}$ ), cuja meta é atender às necessidades dos diversos segmentos do Poder Judiciário brasileiro (Justiça Militar da União e dos Estados, Justiça do Trabalho e Justiça Comum, Federal e Estadual).

Esse sistema inovador foi escolhido para o estudo em pauta por tratar-se de uma tentativa de desburocratização do Judiciário, agindo em prol da eficiência do serviço público, uma vez que proporciona o acompanhamento on-line da tramitação dos processos e a participação mais efetiva e transparente dos profissionais que dele fazem uso. O software foi desenvolvido pelo CNJ a partir da experiência e com a colaboração de diversos tribunais brasileiros (Conselho Nacional de Justiça, 2010), e foi adotado por Tribunais em todo o país. No Tribunal de Justiça do Distrito Federal e Territórios(TJDFT), sua implementação iniciou em julho de 2014, com os Juizados Especiais Cíveis e Juizado Especial da Fazenda Pública do Distrito Federal,ambos do Fórum Desembargador Júlio Leal Fagundes. O comitê gestor do Processo Judicial eletrônico no TJDFT estabeleceu, por meio de um cronograma de implementação disponível no sitio eletrônico do TJDFT, que, até 2018, o sistema estará funcionando em todas as varas do Tribunal. O impacto do PJe pode ser percebido no fato de que, em fevereiro de 2017, alcançou o total de 200 mil processos distribuídos no período médio de dois anos e meio de sua implementação.

A partir dessas reflexões, este estudo tem por intuito responder a seguinte questão: Qual é a percepção dos advogados em relação à adoção e implementação do Processo Judicial eletrônico no TJDFT?

Para operacionalizar a pergunta de pesquisa, o objetivo geraldeste trabalho é analisar a adoção e implementação do PJe no TJDFT sob a percepção dos advogados, por serem os usuários mais ativos no sistema. Os objetivos específicos delimitados foram: Identificar a percepção dos advogados sobre o 
sistema PJe; identificar os fatores positivos e negativos relacionados àadoçãodo PJesob a percepção dos advogados; e categorizar as percepções dos advogados quanto ao sistema PJe.

Este estudo justifica-se devido à necessidade de ampliação da discussão de inovação no Judiciário brasileiro, por ser um sistema complexo que apresenta problemas críticos, tais como a burocratização, lentidão e elevados números de processos (Sadek, 2004; Vieira \& Pinheiro, 2008; Renault, 2005). Além disso, é necessária a realização de estudos que permitam a verificação de satisfação com base na percepção do usuário, pois essa avaliação infere na eficiência do setor público e no valor agregado final da prestação do serviço. Este estudo também investiga a percepção do principal usuário da inovação sendo implementada, o advogado. Essa percepção é essencial para agregar valor e qualidade à tecnologia em desenvolvimento (Shim et al., 2010). Dessa forma,a relevância deste estudo está pautada na ampliação de pesquisas empíricas sobre a implementação de sistemas no serviço público, na perspectiva do usuário, e sobre inovação no Poder Judiciário, contribuindo, de forma geral, para o aperfeiçoamento da administração judicial.

\section{Inovação no setor Público e no Judiciário}

Inovação no setor público pode ser conceituada como a implementação deliberada de novas formas de ação social,as quaisgeram resultados para as entidades que as adotam no contexto dos objetivos e funcionalidades de suas atividades. Dessa forma, a inovação é a expressão das intenções e objetivos do agente social, moldados pelo contexto sociocultural e socioeconômico em que está inserido. Em outras palavras, inovar é fazer algo diferente de forma deliberada para atingir determinados objetivos e as razões para isto são moldadas pelo ambiente do indivíduo ou entidade social (Koch \& Hauknes, 2005).

Novas tecnologias de informação e comunicação - NTIC's, novas práticas de trabalho e novas formas de organização social tornaram a sociedade mais exigente em relação aos serviços prestados pelo Estado. Exigências que pressionam as organizações públicas a diminuir custos, reduzir desperdícios e melhorar a eficiência, sendo indispensável aadoção de inovações para atenderàs demandas (Lekhi, 2007).

Uma parte importante da estrutura de incentivo àinovação no setor público está relacionada à segurança do emprego e probabilidade de promoções do sistema. Inovações que mantenham a conformidade com o sistema atual são mais bem recebidas do que as mais arriscadas, que causam mudanças mais profundas. Assim, sistemas de posse facilitam a geração de modelos coletivos, tanto dentro como entre organizações, causando um alinhamento nas escolhas e estratégias individuais (Koch \& Hauknes, 2005).Desse modo, Freitas e Medeiros (2015) enfatizam que, apesar dos esforços de alguns indivíduos na tentativa de incorporar as tecnologias em sua rotina, as inovações podem entrar em conflito com as práticas e normas estabelecidas na instituição. Isso decorre da influência dos mecanismos sociais e estruturais nas relações institucionais.

O Poder Judiciário brasileiro, setor público investigado por esta pesquisa, apresenta uma série de problemas críticos que afetam o seu desempenho, como uma estrutura grande e complexa, lenta e incapaz de gerar soluções previsíveis, em um prazo razoável e comcusto acessívelpara todos. Esses problemas são causados, em parte, pelo crescimento no número de novos processos todos os anos, o elevado número de recursos previstos pela lei, formalidades protelatórias nas audiências, bem como o formalismo cartorial excessivo (Sadek, 2004; Vieira \& Pinheiro, 2008). Essa estrutura induz outros problemas, como pouca transparência da máquina pública, dificuldade de acesso, desarticulação institucional, lentidão na tramitação dos processos judiciais, obsolescência administrativa, complexidade estrutural e concentração de litigiosidade, devido ao elevado número de processos que interessam ao governo federal e às grandes organizações privadas (Renault, 2005).

Dessa forma, a solução para os problemas públicos que não podem ser solucionados pelo aumento da utilização de verbas e recursos, passa a ser a geração e implementação de soluções inovadoras (Torfing, 2013). A partir da Reforma do Judiciário, implementadapelaEmenda Constitucional $n^{\circ} 45$, de 08 de dezembro de 2004, importantesinovações foram propostas no âmbito do Judiciário brasileiro, voltadas ao aumento datransparência e da eficiência, bem como à realização do princípio da segurança jurídica em um 
maior grau.Dentre essas inovações, destaca-se a criação do: (1) CNJ, (2) Instituto da súmula vinculante, e (3) Requisito de repercussão geral dos recursos extraordinários.

Com a criação do $\mathrm{CNJ}$, órgão de cúpula encarregado de promover a gestão das ações no âmbito administrativo de forma uniforme, as medidas adotadas partem do pressuposto de participação democrática entre os órgãos para elaboração diagnóstica e de planejamento. O CNJ promoveu no Judiciário um espaço para formulação de propostas que abrangessem o futuro, bem como um espaço para pensar sobre a insuficiência do Judiciário no atendimento às demandas sociais (Vieira \& Pinheiro, 2008). Nesse sentido, o CNJ editou várias resoluções com o intuito de viabilizar a informatização do Poder Judiciário brasileiro, que determina diretrizes para a adoção de tecnologias da informação, bem como utiliza a tecnologia no suporte às suas ações, comoverificado em $35 \%$ de suas resoluções publicadas (Lima \& Cruz, 2011).

Essa busca por maior eficiência e celeridade no Judiciário e a implementação das resoluções do $\mathrm{CNJ}$ demandam que os órgãos passem por um processo de mudança organizacional intenso. A gestão da mudança, nesses casos, é um fator fundamental para o sucesso ou fracasso da inovação. Uma das principais questões que afetam as mudanças é a atitude dos funcionários perante o novo processo, bem como a comunicação com todos os atores envolvidos (Miller, Johnson, \& Grau, 1994; Rafferty, Jummieson \& Armenakis, 2013). Entre os fatores que influenciam a mudança de atitudes perante o novo, pode-se citar a forma como as informações são apresentadas, o tamanho da mudança, a credibilidade da organização e as características pessoais dos envolvidos no processo (Rodrigues, Assmar, \& Jablonski, 2009). Outras variáveis do contexto organizacional, como o conteúdo da mudança, o processo decisório, a centralização das decisões e o sistema de comunicação, também são relevantes para a adoção da inovação (Van de Vem \& Sun, 2011).

A adoção da tecnologia está diretamente relacionada à tendência de aceitação dos atores envolvidos, para que se possa implementar novas Tecnologias da Informação e Comunicação de forma que venham a reproduzir e fortalecer mecanismos sócio-estruturais institucionalizados (Fountain, 2005). Nesse sentido, Freitas e Medeiros (2015) asseveram que os atores envolvidos na adoção de tecnologias tendem a moldar as suas práticas com base em um sistema de práticas e normas pré-estabelecidas, dessa forma a tecnologia proposta nunca é implementado exatamente como foi planejada em seu desenvolvimento. Assim, a tendência é que as instituições adotem a tecnologia que foi socialmente aprovada do que a pensada na fase inicial. Dessa forma, a aceitação de mudanças e a adoção de tecnologias dependem de diversos fatores, relacionados não apenas à aspectos tecnológicos da ferramenta, mas também ao contexto organizacional.

\section{Processo Judicial eletrônico}

O processo eletrônico foi aprovado por meio da Lei 11.419/2006 e consiste na tramitação de processos judiciais através de meio eletrônico, preferencialmente pela internet, sendo possível a prática de atos processuais, bem como a transmissão de peças processuais produzidas pelos seus autores. Almeida Filho(2010) argumenta que, dentro da nova ordem processual, o processo eletrônico é mais um instrumento à disposição do Judiciário na busca de maior agilidade na comunicação dos atos processuais e de todo o procedimento. Contudo, o processo eletrônico deve ser precedido de toda a segurança e cautela, e não se pode admitir tratar-se de uma panaceia para os males do Judiciário. Ainda segundo o autor, as decisões judiciais devem acompanhar aevolução da sociedade e do próprio processo, pois sem esse alinhamento essa iniciativa pode se tornar anacrônica.

Por sua vez, o CNJ tem um papel importante na implementação do processo eletrônico,visto que editou várias resoluções para viabilizar a informatização de todo o Poder Judiciário brasileiro, incluindo, dentre elas, a Resolução n 41/2007, que institui o domínio primário "jus.br" para todos os sítios eletrônicos do Poder Judiciário, e a Resolução o $n^{\circ}$ 45/2007, que trata da padronização dos endereços eletrônicos dos órgãos do Judiciário.Vale destacar ainda a Resolução n 70/2009, que dispõe sobre o Planejamento e a Gestão Estratégica no âmbito do Judiciário e dá outras providências, sendo uma delas o estabelecimento de dez metas nacionais de nivelamento a serem cumpridas pelos Tribunais no que tange ao uso das tecnologias da informação e da comunicação,dentre as quais estão: (3) Informatizar todas as unidades 
judiciárias e interligá-las ao respectivotribunal e à rede mundial de computadores (internet); (4) Informatizar e automatizar a distribuição de todos os processos e recursos; (5) Implantar sistema de gestão eletrônica da execução penal e mecanismo de acompanhamento eletrônico das prisões provisórias; (7) Tornar acessíveis as informações processuais nos portais da redemundial de computadores (internet), com andamento atualizado e conteúdo das decisões de todos os processos, respeitado o segredo de justiça; (10) Implantar o processo eletrônico em parcela de suas unidades judiciárias.

Assim, com o objetivo de atender às necessidades dos diversos segmentos do Poder Judiciário brasileiro, o CNJ lançou o PJe, sistema em que ocorrem as tramitações dos processos. O projeto é resultado da união de requisitos definidos pela Justiça Federal com as revisões empreendidas no âmbito do CNJ a fim de assegurar a possibilidade de utilização nos diversos segmentos. Assim, osoftware foi desenvolvido pelo CNJ a partir da experiência e com a colaboração de diversos tribunais brasileiros (Conselho Nacional de Justiça, 2010).

Sua implementação foi realizada com base na Resolução $n^{\circ} 185$, de 18 de dezembro de 2013, que institui o PJe como um sistema de processamento de informações e prática de atos processuais e estabelece os parâmetros para sua implementação e funcionamento.Está previsto em seu artigo segundo que o sistema compreenderá o controle social do sistema judicial nos seguintes aspectos: (I) Ocontrole da tramitação do processo; (II) Apadronização de todos os dados e informações compreendidas pelo processo judicial; (III) Aprodução, registro e publicidade dos atos processuais; e (IV) Ofornecimento de dados essenciais à gestão das informações necessárias aos diversos órgãos de supervisão, controle e uso do sistema Judiciário.

O PJe foi lançado oficialmente em 2011, mas somente a partir de 2014 o CNJ deu início àutilização exclusivado sistema para o trâmite de novos processos. Os processos em andamento também estão sendo migrados do sistema e-CNJ para o PJe (Conselho Nacional de Justiça, 2014). Dentre os Tribunais que aderiram ao sistema, está o TJDFT, que teve sua implementação iniciada em julho de 2014, nos sete Juizados Especiais Cíveis do Fórum Leal Fagundes.Otribunal apresenta ainda um cronograma de implementação do PJe em outras varas, com expectativa de finalização da implementação em 2018.

\section{Metodologia}

A presente pesquisa classifica-se como empírica, de caráter exploratório e descritivo e abordagem qualitativa (Sampieri, Collado \& Lucio, 2006). A opção pelo TJDFT para realização deste estudo se justifica devido àacessibilidadeaos dados, bem como pelos números observados em aproximadamente três meses de implementação do sistema.A previsão é que até 2015 todos os novos processos tramitem eletronicamente.

A primeira etapa, antes do início da coleta de dados, foi a análise de documentos referentes ao sistema do PJe.Essas informações foram utilizadas para entender a organização e analisar a implementação do sistema no TJDFT, bem como compreender a perspectiva dos diversos atores envolvidos noprocesso no que tange àadoção de inovaçõespelo Judiciário brasileiro.Os documentos consultados possibilitaram também a construção de um roteiro semiestruturado para a entrevista, eforam disponibilizados pelo CNJ por meio de uma Wiki, cuja atualização das informações é realizada por servidores e responsáveis pela implantação e atualizaçãodo sistema. Foram, então, realizadas 25 entrevistas, que duraram entre 10 e 15 minutos, com advogados que utilizam o PJe do TJDFT. Contribuíram para este estudo os advogados que estavam presentes nos dias de coleta de dados e que aceitaram participar da entrevista e compartilhar as suas percepções. O TJDFT nos disponibilizou uma sala para que pudéssemos realizar as entrevistas, o que permitiu ao pesquisador e entrevistados maior interação e comodidade.Os advogados participantes possuem tempos de atuação distintos no TJDFT, desde 10 meses até 38 anos, de diferentes faixas etárias e de ambos os sexos, possibilitando que o fenômeno fosse investigado sob diferentes óticas e perspectivas, dando uma visão mais completa da percepção dos advogados sobre a adoção do PJe no TJDFT.A figura 1 apresenta os tempos de experiência dos participantes. 


\begin{tabular}{|l|c|}
\hline Escala de tempo de atuação no TJDFT & Frequência \\
\hline Menos de 1 ano & 1 \\
\hline De 1 a 4 anos & 12 \\
\hline De 5 a 10 anos & 9 \\
\hline De 11 a 20 anos & 1 \\
\hline Mais de 20 anos & 2 \\
\hline
\end{tabular}

Figura 1. Tempo de atuação dos participantes no TJDFT

Fonte: Elaborado pelas autoras.

As entrevistas foram guiadas por um roteiro semiestruturado e gravadas na íntegra, com autorização dos participantes, sendoposteriormente transcritas e analisadas. O roteiro foi adaptado da pesquisa de Sousa e Guimarães (2017) e as alterações foram realizadas com a autorização dos autores, no intuito de adequar as perguntas aos advogados e à realidade do trabalho que desenvolvem no tribunal. A saturação teórica ocorreu após 18 entrevistas e nenhuma informação nova foi acrescida pelos últimos 7 participantes, acarretando o fim da coleta de dados. A técnica de análise de conteúdo utilizada foi a categorial, proposta por Bardin (2006), e foi realizada em três etapas: pré-análise, exploração do material com a definição de categorias a posteriorie tratamento dos resultados.As categorias foram trianguladas entre as pesquisadoras e validadas com um terceiro pesquisador.As categorias e subcategorias identificadas no estudo foram: (1) Desenvolvimento e adoção de inovações no Judiciário brasileiro com as subcategorias barreiras e facilitadores; (2) Impactos procedimentais do PJe, com subcategorias de impactos positivos e negativos; (3) Oportunidades de melhorias no sistema; (4) Impactos do PJe para o TJDFT; (5) Impactos do PJe para a celeridade e qualidade das decisões judiciais e (6) Estratégias para o desenvolvimento de competências e suporte ao sistema.Uma vez que os estudos ainda são escassos e não existe uma delimitação clara na literatura, optou-se pela categorização a posteriori, que permite a investigação das informações de maneira exploratória. Apesar disso, observou-se convergência com algumas categorias identificadas nas pesquisas de: Sousa e Guimarães (2017), como barreiras, facilitadores e impactos negativos e positivos;Koch e Hauknes (2005), como barreiras à inovação; e com os estudos de Halvorsenet al. (2005).

\section{Resultados e Discussão}

Os resultados desta pesquisa serão apresentados em seis seções de acordo com as categorias definidas na análise de conteúdo.

\subsection{Desenvolvimento e adoção de inovações no Judiciário brasileiro}

A figura 2 apresenta os principais facilitadores e barreiras levantados pelos advogados que participaram deste estudo com relação ao desenvolvimento e adoção de inovações no Judiciário brasileiro, bem como a frequência de cada item.

\begin{tabular}{|c|c|c|}
\hline Fatores & Frequência & \multicolumn{1}{c|}{ Evidências } \\
\hline $\begin{array}{c}\text { Demanda da } \\
\text { sociedade }\end{array}$ & 1 & $\begin{array}{l}\text { O aspecto que eu acho que facilita é a própria demanda da sociedade que } \\
\text { precisa de processos mais rápidos, então o Judiciário acaba precisando se } \\
\text { adaptar. (Advogado 1) }\end{array}$ \\
\hline \multicolumn{3}{|c|}{ Barreiras } \\
\hline $\begin{array}{c}\text { Tradicionalismo } \\
\text { do Judiciário }\end{array}$ & 3 & $\begin{array}{l}\text { O Poder Judiciário é um órgão muito conservador, então eles resistem a } \\
\text { qualquer inovação.Eles são, de certa forma, acomodados, no sentido de não } \\
\text { querer novidades para não se envolverem e eventualmente não assumirem } \\
\text { riscos. Vejo essa postura normalmente nos juízes, desde juízes substitutos } \\
\text { até desembargadores. Às vezes, a própria cúpula do tribunal, a presidência } \\
\text { e a corregedoria, émais ousada, só que não consegue que a base, a ponta, } \\
\text { termine assumindo e aceitando as inovações que eles estão propondo. Se } \\
\text { não for na marra, não sai. (Advogado 13) }\end{array}$ \\
\hline
\end{tabular}




\begin{tabular}{|c|c|l|}
\hline $\begin{array}{c}\text { Limitação de } \\
\text { recursos }\end{array}$ & 2 & $\begin{array}{l}\text { Acho que o orçamento do Judiciário acaba limitando muito as possíveis } \\
\text { ações. Acho que falta um pouco de recursos humanos, ou a melhor } \\
\text { produtividade das pessoas. (Advogado 6) }\end{array}$ \\
\hline $\begin{array}{c}\text { Resistência dos } \\
\text { servidores }\end{array}$ & 1 & $\begin{array}{l}\text { A mentalidade dos servidores que precisa mudar, isso dificulta muito a } \\
\text { implementação de inovações. (Advogado 2) }\end{array}$ \\
\hline Burocracia & 1 & $\begin{array}{l}\text { Sem dúvida a burocracia que ainda é muito grande no nosso sistema } \\
\text { judiciário.Aassim, eles são muito presos a certos tipos de atos, por exemplo, } \\
\text { às vezes a gente fecha um acordo fora da sala de audiência e a gente tem } \\
\text { que entrar, ouvir toda aquela explicação, e acaba que atrasa e isso dificulta. } \\
\text { (Advogado 25) }\end{array}$ \\
\hline
\end{tabular}

Figura 2. Fatores que influenciam o desenvolvimento e adoção de inovações no Judiciário

Fonte: Elaborado pelas autoras

Conforme apresentado na figura2, apenas um participante apontou um fator facilitador para a inovação, que foi a demanda da sociedade. Esse fator também é apontado por Halvorsenet al. (2005) como um motivador para a inovação no setor público. As barreiras citadas que dificultam a adoção de inovações foram: o tradicionalismo do Judiciário;a limitação de recursos, tanto financeiros quanto humanos;a resistência dos servidores e a burocracia do serviço público. Apesar dos resultados, apenas sete advogados contribuíram para essa categoria. Dos 18 participantes restantes, três não acham que há algumfator que facilita ou dificulta o desenvolvimento e a implementação de inovações no Judiciário;sete deram respostas que não estavam relacionadas ao tema, demonstrando que não entenderam a pergunta mesmo após o esclarecimento dos pesquisadores;e os outros sete não responderam a pergunta.

Esses resultados permitem inferir que a maioria dos advogados entrevistados não tem conhecimento acerca do Judiciário ou do próprio setor público. Sobre a barreira burocrática, levantada por apenas um dos respondentes, vale citar que,paraHalvorsenet al. (2005), o serviço público geralmente é visto como um sistema extremamente lento, rígido, hierárquico e com departamentos especializados, que apresenta limites de autoridade ambíguos, bem como possui, na maioria das vezes, um sistema burocrático institucionalizado com o "modo de fazer as coisas" definido, o que seria uma barreira à inovação. Assim, sabe-se que a inovação requer um sistema dinâmico e complexo, com base nas interações e na comunicação.

Algumas outras questões citadas na literatura também foram apontadas, como a morosidade do Judiciário, o excesso de formalismo cartorial, formalidades protelatórias nas audiências, deficiências na gestão dos recursos (Sadek, 2004; Vieira \& Pinheiro, 2008; Stumpf, 2009) e dificuldade em assumir riscos (Koch \& Hauknes, 2005). Ainda assim, esses advogados levantaram apenas um ponto cada um, ou seja, nenhum participante demonstrou visão sistêmica da situação atual do Judiciário. Além disso, não foram apontadas outras questões citadas na literatura,tais como: o tamanho e a complexidade do serviço público, que reflete na escala e ritmo da mudança; a falta de agilidade e as barreiras técnicas e de aprendizagem organizacional (Koch \& Hauknes, 2005). Talvez por estarem alheios a essas questões, os advogados não observem as iniciativas do TJDFT para dar suporte a utilização do sistema, melhorar as rotinas e os resultados da inovação. Nesse ponto, observa-se que a integração entre o Judiciário e os advogadospoderia melhorar, agregando valor naprestação do serviço.

\subsection{Impactos Procedimentais}

O desenvolvimento de uma compreensão mais ampla da inovação na produção de serviços vai muito além da compreensão do impacto das políticas públicas e da regulação.Assim,qualquer entendimento de teorias sociais de inovação funcional exigem a necessidade de compreensão das dimensões sistêmicas do desempenho da inovação (Halvorsen et al., 2005).É importante esclarecer que a palavra impacto, neste trabalho, foi adotada no sentido de "provocar mudanças", ou seja, a percepção dos advogados sobre as possíveis mudanças, positivas e negativas, que a implementação do PJe poderá gerar. Esse entendimento vai ao encontro da definição de impacto que consta no dicionário Michaelis da língua portuguesa, a saber: "efeito que, por sua força, impede ou acarreta mudanças". 
Os impactos positivos foram medidos por meio da frequência com que foram elencados no discurso dos entrevistados. Assim, de acordo com a figura 3, percebe-se que o ponto elencado como maior frequência foi a redução de idas ao Tribunal,citado por 14 advogados, uma vez que, com a informatização dos dados, os advogados precisam ir ao Tribunal apenas para as audiências e para questões pontuais.A redução de custos também foi muito reincidente nas entrevistas. Os advogados afirmam que essa economia beneficia os advogados e o Tribunal, pois interfere de maneira direta nos custos, com papel, combustível, entre outros recursos anteriormente utilizados. Acredita-se ainda que o PJe possa impactar na diminuição do número de servidores necessários ao Tribunal. Esses resultados corroboram com a visão de Bezerra (2009), que afirma que benefícios, como a redução dos custos, do tempo de tramitação dos processos e a melhoria da qualidade dos serviços, são resultados esperados pela revolução tecnológica no Judiciário brasileiro. Corroboram também com os resultados encontrados por Freitas e Medeiros (2015)em pesquisa realizada no Superior Tribunal de Justiça, no ano de 2015, que objetivou identificar os principais fatores que facilitam ou inibem a adoção de tecnologias. Os resultados dessa pesquisa apontam que, para os advogados, os sistemas eletrônicos possibilitam mais oportunidades de trabalho emaior agilidade e celeridade nos processos judiciais.

\begin{tabular}{|c|c|c|}
\hline Impactospositivos & Frequência & Evidências \\
\hline $\begin{array}{l}\text { Redução de idas } \\
\text { ao tribunal }\end{array}$ & 14 & $\begin{array}{l}\text { A mudança mais significativa que você tem com o PJe é que o advogado } \\
\text { não precisa se deslocar tanto para o Tribunal, para a Vara ou para o Cartório } \\
\text { para conseguir ter acesso a um processo ou a uma documentação para } \\
\text { você conseguir fazer uma defesa. (Advogado 19) }\end{array}$ \\
\hline Redução de custos & 10 & $\begin{array}{l}\text { Auxilia muito a questão de custos com protocolo, tanto de pessoal, quanto } \\
\text { de combustível, papel, tinta, cópias, etc. (Advogado 22) }\end{array}$ \\
\hline $\begin{array}{l}\text { Flexibilidade de } \\
\text { horários para } \\
\text { peticionar }\end{array}$ & 9 & $\begin{array}{l}\text { Acho que o PJe também aumenta a qualidade do trabalho do advogado } \\
\text { porque você pode acessar o processo de qualquer lugar, tem um prazo } \\
\text { maior para peticionar, você não fica a mercê de um horário de } 12 \mathrm{~h} \text { às } 19 \mathrm{~h} \text {. } \\
\text { Então ganha em qualidade nessa questão, não fica preso se o processo } \\
\text { já foi concluso ou não, você tem pleno acesso. (Advogado 19) }\end{array}$ \\
\hline $\begin{array}{l}\text { Facilidade no } \\
\text { acesso aos autos }\end{array}$ & 6 & $\begin{array}{l}\text { Acesso mais rápido aos autos, o advogado não precisa mais tirar cópia. } \\
\text { (Advogado 17) }\end{array}$ \\
\hline $\begin{array}{c}\text { Desnecessidade } \\
\text { de carregar os } \\
\text { processos }\end{array}$ & 4 & $\begin{array}{l}\text { O aspecto que eu acho que mais impactou até agora foi na questão de } \\
\text { não ter que ficar carregando processo. (Advogado7) }\end{array}$ \\
\hline $\begin{array}{l}\text { Agilidade no tramite } \\
\text { processual }\end{array}$ & 4 & $\begin{array}{l}\text { A agilidade do andamento processual, o PJe melhora muito nesse ponto, } \\
\text { porque você faz tudo digital e você agiliza, assim o juiz consegue dar uma } \\
\text { decisão mais rápida, mais célere. (Advogado 5) }\end{array}$ \\
\hline $\begin{array}{l}\text { Melhoria na gestão } \\
\text { do tempo do } \\
\text { advogado }\end{array}$ & 4 & $\begin{array}{l}\text { O lado bom é que diminui a nossa vinda ao fórum, acelera o processo, } \\
\text { economiza tempo e dinheiro pra gente. (Advogado } 8 \text { ) }\end{array}$ \\
\hline $\begin{array}{l}\text { Informatização dos } \\
\text { dados }\end{array}$ & 2 & $\begin{array}{l}\text { Você tem todos os seus dados informatizados através do seu "token",você } \\
\text { tem acesso em casa, no escritório ou até fora dele, você pode acessar o } \\
\text { processo sem ter que estar levando aquele peso morto.Você tem tudo } \\
\text { eletronicamente, isso é altamente positivo. (Advogado 2) }\end{array}$ \\
\hline $\begin{array}{l}\text { Agilidade na } \\
\text { distribuição dos } \\
\text { processos }\end{array}$ & 1 & $\begin{array}{l}\text { O PJe melhorou muito a celeridade do processo, porque antes, quando a } \\
\text { gente entrava com uma ação aqui no CEJUSC, você só sabia o juizado } \\
\text { que o processo seria distribuído depois da audiência de conciliação, } \\
\text { agora não, quando você entra com uma ação, o advogado já sabe pra } \\
\text { qual Juizado ele será distribuído. Isso ajuda muito, porque o advogado } \\
\text { consegue saber qual tem sido o entendimento daquele Juizado e qual } \\
\text { deverá ser o posicionamento. (Advogado 22) }\end{array}$ \\
\hline
\end{tabular}

Figura 3. Impactos positivos do PJe

Fonte: Elaborado pelas autoras 
Aflexibilidade de horários para peticionar e a facilidade no acesso aos autos impactam positivamente na gestão do tempo do advogado. No que tange à agilidade no trâmite processual, quecolabora para a diminuição da morosidade no Poder Judiciário (STUMPF, 2009), vale destacar a geração de opções para combate às causas externas da morosidade, por meio da Resolução n॰. 185, de 18 de dezembro de 2013, e a adoção de tecnologias no combate àscausas internas. Essa resolução prevê vantagens advindas da adoção de instrumentos tecnológicos que permitam a adequação do funcionamento do Poder Judiciário aos princípios da proteção ambiental, o que pode ser observado nas falas de alguns advogados no que tange aocorte de custos com papel e outros artefatos administrativos. Esses impactos positivos destacam a importância de se gerar opções inovadoras no setor público com vias a facilitar as ações executadas pelo cliente final.

De acordo com os entrevistados, o PJe também causa impactos procedimentais negativos. Vale ressaltar que as barreiras à inovação no setor público podem tercausas ou efeitos oriundos de várias interações complexas (Koch \& Hauknes, 2005). De acordo com os resultados obtidos por meio das entrevistas realizadas, observam-se que os impactos negativos citadosse referemàs limitações técnicas do sistema, como tamanho de arquivos, especificações de localização de informações, adequação de perfis, possibilidades distintas para determinados arquivos eadequação do sistema para envios de blocos de arquivos compostos por várias laudas de uma única vez, ao invés de anexar página a página. Também foi citada a inconsistência do sistema, que gera transtornos, como sistema fora do ar etravamentos, entre outras dificuldades. Sobre o acesso ao sistema, a maior dificuldade está relacionada aos advogados mais experientes e que possuem algumas limitações com as TIC's. Esse resultado é corroborado por Freitas e Medeiros (2015), visto que advogados com maiores dificuldades no uso de tecnologias percebem maiores barreiras de adaptação.

\begin{tabular}{|c|c|l|}
\hline Impactos Negativos & Frequência & \multicolumn{1}{c|}{ Evidências } \\
\hline $\begin{array}{c}\text { Limitações técnicas } \\
\text { do sistema }\end{array}$ & 12 & $\begin{array}{l}\text { AcheioPJe muitoinconsistente.Você tenta juntar os documentos, não } \\
\text { consegue.Tem limite de caracteres no nome do arquivo, acho que são } \\
\text { 200 no máximo. Tambémachei pouco o tamanho dos arquivos, apenas } \\
\text { 2,5Mb. (Advogado3) }\end{array}$ \\
\hline $\begin{array}{c}\text { Inconsistência do } \\
\text { sistema }\end{array}$ & 9 & $\begin{array}{l}\text { Às vezes, o sistema não faz o upload dos arquivos. Às vezes, trava, dá } \\
\text { erro, fica fora do ar, e o advogado tem que ficar muito tempo tentando. } \\
\text { (Advogado 17) }\end{array}$ \\
\hline $\begin{array}{c}\text { Dificuldades de } \\
\text { acesso ao sistema }\end{array}$ & 5 & $\begin{array}{l}\text { O problema é que a gente não tem esse trato com a computação.Eu } \\
\text { sou do tempo da máquina de datilografia. Para o computador, foi uma } \\
\text { adaptação.Eagora, com tudo digital, complicou ainda mais para utilizar. } \\
\text { Às vezes, você quer abrir o processo, você entra no sistema e tem } \\
\text { dificuldade em manusear as folhas. (Advogado 23) }\end{array}$ \\
\hline $\begin{array}{c}\text { Complexidade do } \\
\text { sistema }\end{array}$ & 5 & $\begin{array}{l}\text { Eles adotaram o sistema eletrônico, mas, por estar no começo, tem } \\
\text { algumas coisas que estão falhando, pois eles elaboraram o processo } \\
\text { para uma classe da sociedade que é altamente esclarecida, quando a } \\
\text { finalidade do juizado especial é atender a uma parcela da sociedade } \\
\text { que não tem essa informatização toda. (Advogado 2) }\end{array}$ \\
\hline $\begin{array}{c}\text { Necessidade de } \\
\text { uniformização do } \\
\text { sistema }\end{array}$ & 3 & $\begin{array}{l}\text { Acho que tinha que ser um sistema único para todos os tribunais } \\
\text { do Brasil, isso facilitaria as atividades dos advogados também. E os } \\
\text { advogados acabam tendo que ter vários certificados digitais, um para } \\
\text { cada sistema. (Advogado 9) }\end{array}$ \\
\hline
\end{tabular}

Figura4. Impactos negativos do PJe

Fonte: Elaborado pelas autoras

Um ponto interessante suscitado pelas entrevistas foi auniformização do sistema, uma vez que, segundo os entrevistados, cada estado e cada tribunal possuem um sistema diferente, o que dificulta o acesso e o manuseio das ações procedimentais. Essa uniformização vai ao encontro da ideia de difusão da inovação, defendida por Rogers (1983), como uma forma de mudança social, ou seja, a adoção de inovações gera um processo que pode alterar a estrutura e função de um sistema social.O autor defende 
ainda o componente da incerteza no processo de difusão e a informação como uma forma de reduzir a incerteza dos efeitos da inovação. Isto posto, observa-se a necessidade de interoperabilidade nos sistemas de judiciários no Brasil.A falta de padronização e intercomunicação entre os sistemas resulta em uma grande perda de tempo para os advogados, uma vez que eles precisam desenvolver habilidades e aprender a lidar com cada um. A interoperabilidade é, portanto, vista como uma meta urgente e fundamental que deve ser alcançada (Freitas \& Medeiros, 2015).

\subsection{Oportunidades de melhorias no sistema}

No processo de implementação e utilização de um novo sistema, é importante investigar as percepções dos usuários e identificar as oportunidades de melhoria (Shim et al., 2010). Os advogados que participaram da pesquisa também sentem esse distanciamento entre o Judiciário e os advogados, e apontaram para a necessidade do TJDFT realizar pesquisas junto aos usuários do PJe.

Acredito que uma ferramenta nunca está fechada, sempre terá a necessidade de uma evolução e essa evolução ocorre ouvindo quem utiliza o sistema. No caso do PJe, seria tanto ouvir o lado do servidor quanto o lado do advogado, porque o Judiciário parece muito distante dos advogados. (Advogado 8)

As oportunidades de melhoria no PJe identificadas pelos advogados entrevistados estão de acordo com os impactos negativos discutidos na seção anterior. Os fatores e oportunidades de melhoria mais citados estavam relacionados à disponibilidade, confiabilidade, qualidade e facilidade de acesso e ao funcionamento do sistema. Sobre a disponibilidade do sistema, os advogados citaram que o sistema se configura como instável e possui muitas divergências de navegação. A confiabilidade abordou fatores como erros frequentes no upload de arquivos e falhas que geram a perda de arquivos. Essas questões acabam gerando certa resistência e insegurança na utilização do sistema do PJe, pois os advogados passam a questionar a eficiência e os reais benefícios da tecnologia.ParaKoch e Hauknes (2005), a resistência a implementação de inovações por parte do usuário final é uma barreira à inovação no setor público que pode ser gerada por fatores como idade, acesso àstecnologias da informação e comunicação, origem técnica,entre outras. Um dos advogados inclusive citou um caso ocorrido durante um treinamento na Ordem dos Advogados do Brasil - OAB, conforme apresentado abaixo.

Tenho restrições com relação à confiabilidade do sistema. Eu acho que o PJe facilita, mas a questão é ser um sistema confiável, porque, quando nós fizemos o treinamento da OAB,e fizemos uma simulação, um dos arquivos lá se perdeu. (Advogado 6)

Já com relação à qualidade, houve críticas para alimitação de tamanho de arquivo, que os obriga a fragmentar.Compactar ou não apresentar o conteúdo da forma que consideram mais apropriada. $O$ sistema também não apresenta todas as opções necessárias para preenchimento nos campos disponíveis conforme relatado pelos advogados.

Quando você precisa colocar arquivos muito grandes, ele não permite ou trava. Sempre que precisei protocolar alguma coisa, deu problema, deu erro. Estão faltando alguns possíveis atores do processo, como leiloeiro, por exemplo. Tem também a questão da constante necessidade de atualizar o JAVA. Ainda tem muita coisa para melhorar. (Advogado 13)

Sobre o funcionamento do sistema e a facilidade de acesso, os advogados entrevistados citaram a frequente necessidade de atualização de linguagens de programação, como o JAVA, e a apresentação do sistema no que tange à acessibilidade, tendo em vista os constantes travamentos e lentidão. Além disso, sobre a facilidade de acesso, os entrevistados sugeriram que o sistema PJeseja simplificado para advogados mais experientes e com idade mais elevada,ou que possuem mais dificuldade para lidar com tecnologias, bem como para que as pessoas que não possuem advogados possam utilizá-lo, uma vez que no Juizado Especial o número de pessoas sem advogados é alto devido ao baixo valor das causas operadas.

Por fim, um dos entrevistados identificou a questão da limitação de recursos financeiros como uma possível barreira ao desenvolvimento de todas essas melhorias, bem como a manutenção do sistema no longo prazo, pois a tendência é que o volume de processos seja cada vez maior. Essa oportunidade de 
melhoria apresentada vai ao encontro das barreiras à inovação apontadas por Koch e Hauknes (2005) no que consiste à ausência de recursos e questões técnicas. Vale ressaltar também que essas barreiras não são mutuamente exclusivas e que um obstáculo pode ser a causa ou efeito de um ou vários outros em um ambiente dinâmico.Assim sendo, a limitação de recursos financeiros pode ser efeito de outras barreiras do setor público, bem como ser a causa de outros obstáculos à inovação.

A figura 5 resume as oportunidades de melhoria apontadas na pesquisa.

\begin{tabular}{|l|c|}
\hline Oportunidade de melhoria & Frequência \\
\hline Disponibilidade do sistema & 4 \\
\hline Confiabilidade do sistema & 8 \\
\hline Qualidade do sistema & 7 \\
\hline Funcionamento do sistema e facilidade de acesso & 11 \\
\hline
\end{tabular}

Figura 5. Oportunidades de melhoria no PJe do TJDFT

Fonte: Elaborado pelas autoras

\subsection{Impactos do PJe para o TJDFT}

Sobre os impactos da implantação do PJe para o TJDFT, verifica-se uma certa dificuldade por parte dos entrevistados em diferenciar os impactos organizacionais de impactos pessoais. Uma possível justificativa para isso é que a inovação é percebida muitas vezes como algo que é forçado por uma ordem exterior e associadaàsmudanças e intervenções políticas. Isto significa que qualquer estudo de inovação no setor público deve também levar em consideração os processos internos (Halvorsen et al., 2005).

Os resultados demonstram que os advogados associam os impactos àredução de custos, de pessoal e melhor organização e divisão do trabalho. É interessante ressaltar tambémqueos entrevistados relacionam a celeridade como um benefício que impacta tanto em suas ações quanto nas ações do tribunalnose refere à eficiência do sistema, devido à agilidade com que os processos são administrados e julgados. Observase ainda que dez entrevistados não souberam ou não quiseram responder, e seis afirmaram ser muito cedo para emitir uma opinião a respeito.A pesquisa realizada por Freitas e Medeiros (2015) enfatiza esse resultado, visto que 95\% dos advogados entrevistados mencionaram que, após a introdução da inovação, observaram economias significativas não só para os escritórios de advocacia, mas também para os seus clientes. A percepção desses participantes vai ao encontro da literatura, que aponta que a adoção de inovações tende a melhorar a eficiência ou o desempenho da organização que a adota(Damanpour \& Gopalakrishnan, 1998).

\subsection{Impactos do PJe para a celeridade e qualidade da decisão judicial}

Com relação ao impacto do PJe na celeridade das decisões judiciais, 16 dos 25 advogados entrevistados percebem o sistema como sendo benéfico para o aumento da agilidade no trâmite dos processos. Ainda que a percepção tenha sido positiva, um dos advogados demonstrou uma certa dúvida a respeito da durabilidade da agilidade trazida pelo sistema, alegando que "por ser novo, acho que eles estão dando um pouco de atenção e prioridade, então tem melhorado a celeridade, mas não sei se ao longo do tempo vai continuar assim" (Advogado 15).

Como o sistema do PJefoi implementado há pouco tempo, 9dos advogados entrevistados ainda não perceberam impactos na celeridade das decisões judiciais e alegaram que não possuíam informações suficientes no momento da entrevista,sendo necessário mais tempo para analisar. Apesar disso, nenhum dos 25 advogados que participaram do estudo percebeu o PJe como tendo um impacto negativo na celeridade.

Ainda que o PJe aumente a agilidade do andamento do processo, alguns advogados levantaram um possível limitador para o aumento da velocidade da decisão judicial, conforme apontado abaixo. 
Agora, com questão a da celeridade também, tudo vai depender, porque o número de juízes continua o mesmo, então ele pode ter 50 processos, como pode ter 100 processos, e tem um momento de exaustão. Então, não sei até que ponto vale a pena, porque pode ser que o juiz vire o gargalo, e tudo fique travado e limitado nele. (Advogado 6)

O PJe só agiliza o processo administrativo. Prova disso é a Justiça Federal, que utiliza o sistema há muito mais tempo e demora muito mais que o TJDFT para julgar. (Advogado 8)

Conforme observado nas citações acima, a restrição de recursos humanos não é um limitante relacionadodiretamente ao sistema, porém pode afetar a celeridade das decisões judiciais. Essa limitação não pode ser resolvida pela implementação de um sistema, pois depende do conhecimento, experiência e esforço cognitivo do juiz.

Já com relação ao impacto na qualidade da decisão, nenhum dos advogados percebe que o PJe possa aumentar esse fator. Dos advogados que participaram da pesquisa, 19 acham que o sistema não afeta a qualidade, alegando que a qualidade independe da forma que a pessoa ou juiz teve acesso ao processo.Além disso, 3entrevistados, afirmaram que não possuem informações suficientes para formar uma opinião a respeito do impacto do PJe para a qualidade das decisões judiciais. Para os outros três o PJepode apresentar impactos negativos para a qualidade. Percebe-se que, apesar da maioria dos entrevistados não achar que o PJeimpactana qualidade da decisão judicial, alguns advogados visualizam a possibilidade de o sistema afetar negativamente esse fator.

\subsection{Estratégias para o desenvolvimento de competências do usuário e suporte ao PJe}

A estratégia para o desenvolvimento de competências mais citado pelos advogados foi o curso promovido pela OAB/DF. Apesar de 14 advogados terem apontado essa estratégia, eles não têm conhecimento se é uma inciativa apenas da Ordem dos Advogados ou se é uma parceria entre o TJDFT e a OAB. Os participantes também colocaram alguns problemas nesse curso, que atrapalham o aprendizado, como a falta de nivelamento nas turmas ea superficialidade na abordagem do tema. Dessa forma, os advogados acabam aprendendo a utilizar o sistema sem auxílio do TJDFT e desenvolvendo essas competências de maneira independente.

Os advogados que não têm facilidade com informática e tecnologias, apresentam mais dificuldades do que os demais e devem recorrer a outros meios para desenvolver essas habilidades, pois nem sempre os servidores estão preparados para ajudar, conforme apontado pelos participantes. Nesse sentido, o apoio técnico do setor público ao decorrer da implementação do sistema é muito importante para que os usuários se sintam mais confortáveis com as mudanças. Esse apoio podeauxiliar na diminuição da barreira de aversão ao risco, pois as inovações raramente são fenômenos isolados e muitas vezes dependem de mudanças e inovações que levam a um efeito cascata em todo o sistema em que são aplicadas (Koch \& Hauknes, 2005).Por outro lado, os advogados que têm facilidade com tecnologias, ou que já utilizam o processo eletrônico de outros tribunais, acharam o sistema autoexplicativo e de fácil utilização e não tiveram maiores problemas. Esses participantes corresponderam a 25\% do total de entrevistados.

Sobre o suporte dado pelo TJDFT para tirar dúvidas rápidas e dar apoio no dia a dia dos usuários, menos de $50 \%$ dos usuários demonstraram conhecimento sobre essas experiências. A figura6 ressalta os principais pontos colocados, a frequência e algumas citações. 


\begin{tabular}{|c|c|l|}
\hline $\begin{array}{c}\text { Suporte aos } \\
\text { advogados }\end{array}$ & Frequência & \multicolumn{1}{c|}{ Evidências } \\
\hline $\begin{array}{c}\text { Atendimento } \\
\text { telefônico }\end{array}$ & 2 & $\begin{array}{l}\text { Já liguei para o suporte do TJDFT e fui muito bem atendido, eles foram } \\
\text { muito atenciosos. (Advogado 5) }\end{array}$ \\
\hline $\begin{array}{c}\text { Não existe } \\
\text { atendimento } \\
\text { telefônico }\end{array}$ & 4 & $\begin{array}{l}\text { Uma solução interessante também seria um bom atendimento por } \\
\text { telefone, pois você está com o problema e já está com o computador } \\
\text { ligado seria muito mais rápido para resolver. (Advogado 4) }\end{array}$ \\
\hline $\begin{array}{c}\text { Atendimento via } \\
\text { email }\end{array}$ & 2 & $\begin{array}{l}\text { O TJDFT só faz atendimento via email, não tem nenhum número que o } \\
\text { advogado possa ligar e tirar dúvidas rápidas por telefone. (Advogado 17) }\end{array}$ \\
\hline $\begin{array}{c}\text { Atendimento } \\
\text { presencial }\end{array}$ & 3 & $\begin{array}{l}\text { No TJDFT tem uma sala que tem vários servidores e atendentes e eles } \\
\text { te dão todo apoio para que você possa acessar o processo. Tem scanner } \\
\text { tem tudo, o atendimento é muito bom. (Advogado 2) }\end{array}$ \\
\hline $\begin{array}{c}\text { Manuais no site do } \\
\text { TJDFT }\end{array}$ & 1 & $\begin{array}{l}\text { Tem alguns manuais no site do TJDFT sobre o PJe e o email de suporte, } \\
\text { não tem telefone. (Advogado 24) }\end{array}$ \\
\hline
\end{tabular}

Figura 6: Meios oferecidos pelo TJDFT para dar suporte aos advogados

Fonte: Elaborado pelas autoras

Percebe-se que, além dessas estratégias não terem sido muito bem divulgadas entre os advogados, existe uma divergência entre opiniões, principalmente emrelação ao atendimento por telefone. Ademais, 3advogados nunca tiveram conhecimento de nenhuma estratégia do TJDFT para desenvolver as competências necessárias para utilização do sistema ou para dar suporte aos usuários, o que pode demonstrar falhas na comunicação entre o tribunal e os advogados.Como limitações dapesquisa, pode-se citar que a coleta de dados foi realizada em meio à implementação do sistema, cuja conclusão em todas as circunscrições do TJDFT deverá ocorrer até o final de 2015. Por um lado, essa percepção imediata pode ser interessante para a análise de impactos da adoção, mas, por outro, ainda é prematura e pode sofrer alterações ao longo dos próximos anos. Outro aspecto limitador refere-se ao acesso ao Judiciário como um campo de pesquisa, uma vez que a organização desse setor acaba gerando uma série de limitações burocráticas que dificulta a realização de pesquisas acadêmicas.

\section{Conclusão}

Os resultados obtidos corroboram a ideia de que existe a necessidade de ampliação da adoção e difusão de inovações no Poder Judiciário, visto que a difusão é uma forma de mudança social que pode alterar a estrutura e função de um sistema (Rogers, 1983). Nesse sentido, Bezerra (2009) assevera que o desafio das inovações tecnológicas incorporadas ao mundo jurídico é possibilitar a redução de custos, o tempo de tramitação dos processos e a melhoria da qualidade dos serviços prestados. Os advogados que participaram da entrevista percebem essas questões como possíveis impactos positivos do PJe para o TJDFT, corroborando com o estudo de Bezerra (2009).

Ademais, os dados obtidos nesta pesquisa enfatizam a importância de variáveis organizacionais, principalmente o envolvimento com todos os atores que utilizarão a nova tecnologia e a comunicação. Os participantes demonstraram dificuldade em distinguir os possíveis impactos da adoção da inovação para a organização e os resultados pessoais. Essa dificuldade reflete também na falta de visão sistêmica da situação atual do Judiciário.A baixa compreensão sobre o serviço público e sobre os desafios do Judiciário de forma geral pode gerar visões enviesadas sobre a realidade e insatisfações.Quando os stakeholders são envolvidos na prestação do serviço, aumenta a compreensão sobre o serviço, melhora a prestação dele e potencializa o surgimento de outras inovações, agregando valor ao cliente final (Bitner, Faranda, Hubbert \& Zeithaml, 1997). Essa coprodução traz benefícios para ambas as partes que, por meio da cooperação, conseguem reduzir insatisfações e potencializar o resultado gerado (Bettencourt, Ostrom, Brown \& Roundtree, 2002). Dessa forma, uma maior integração entre o Judiciário e os advogados pode ser benéfica para ambas as partes, bem como para a sociedade receptora do serviço. 
Além dos resultados apresentados na seção anterior, este trabalho identificou que, apesar de o PJe ter sido implementado para aumentar a eficiência e a celeridade dos processos judiciais, o que ocorreu, na percepção dos advogados, foi a alteração do gargalo, que deixou de ser nas etapas iniciais de tramitação dos processos e passou para o julgamento do juiz. Assim, pode ser que a melhoria na celeridade das decisões judiciais não seja tão evidente, devido àsrestrições de recursos humanos.

Portanto, recomenda-se como agenda de pesquisa a realização de estudos semelhantes com os servidores, juízes e gestores do PJe no TJDFT para analisar a percepção dos usuários internos e dos especialistas que dão suporte ao sistema. Essa pesquisa também poderia ser realizada em outros tribunais que adotaram o PJe, tanto com os advogados quanto com os servidores, para que os resultados possam ser comparados com os do presente estudo. Vale ressaltar que o Poder Judiciário brasileiro está passando por mudanças que visam ultrapassar o período de "crise no Judiciário" eseria interessante que outros estudos buscassem analisar as políticas de inovações tecnológicas propostas pelo CNJ, tendo em vista que $35 \%$ das resoluções expedidas são referentes àadoção de tecnologias da informação (Lima \& Cruz, 2011). Por fim, essa pesquisa poderia ser replicada futuramente, após a implementação do sistema em todo o TJDFT, com o objetivo de verificar mudanças na percepção dos usuários e resultados mais precisos com relação aos benefícios do sistema para a celeridade e eficiência das decisões judiciais.

\section{Referências}

Almeida, J. C. A., Filho. (2010). Processo eletrônico e teoria geral do processo eletrônico: A informatização judicial no Brasil (3a ed.). Rio de Janeiro: Forense.

Bardin, L. (2006). Análise de Conteúdo. Lisboa: Edições 70.

Bezerra, M. T. (2009). O processo virtual como instrumento de acesso à justiça no Juizado Especial Federal da subseção judiciária de Sobral/CE. Revista ESMAFE, 19(2), 337- 380.

Bettencourt, L. A., Ostrom, A. L., Brown, S. W., \& Roundtree, R. I. (2002). Client coproduction in knowledgeintensive business services. California Management Review, 44(4), 100-128.

Bitner, M. J., Faranda, W. T., Hubbert, A. R., \&Zethaml, V. A. (1997).Customer contributions and roles in service delivery. International Journal of Service Industry Management, 8(3), 193-205.

Brasil. Presidência da República (2006). Lei $n^{\circ}$ 11.419, de 19 de dezembro de 2006. Dispõe sobre a informatização do processo judicial; altera a Lei no 5.869, de 11 de janeiro de 1973 - Código de Processo Civil e dá outras providências. Retirado de http://www.planalto.gov.br/ccivil_03/_ato20042006/2006/lei/ I11419.htm

Conselho Nacional de Justiça (2007). Resoluçãon ${ }^{\circ}$ 41, de 11 de setembro de 2007. Institui o domínio primário "jus.br" para todos os sítios eletrônicos do Poder Judiciário. Retirado de http://www.trtsp.jus. br/geral/tribunal2/Trib_Sup/STF/CNJ/Res_41_07.html

Conselho Nacional de Justiça (2007). Resolução $n^{\circ} 45$, de 17 de dezembro de 2007. Dispõe sobre a padronização dos endereços eletrônicos dos órgãos do Poder Judiciário brasileiro. Retirado de http:// www.trtsp.jus.br/geral/tribunal2/Trib_Sup/STF/CNJ/Res_45_07.html

Conselho Nacional de Justiça (2009). Resolução $n^{\circ}$ 70, de 18 de março de 2009. Dispõe sobre o Planejamento e a Gestão Estratégica no âmbito do Poder Judiciário. Retirado de http://www.trtsp.jus. br/geral/tribunal2/Trib_Sup/STF/CNJ/Res_70_09.html

Conselho Nacional de Justiça (2010). Processo Judicial Eletrônico - Pje. Brasília. Retirado de http://www. trtsp.jus.br/servicos/pje

Conselho Nacional de Justiça (2013). Resolução $n^{\circ} 185,18$ de dezembro de 2013. Institui o Sistema Processo Judicial Eletrônico - PJe como sistema de processamento de informações e prática de atos processuais e estabelece os parâmetros para sua implementação e funcionamento. Retirado de http:// www2.trtsp.jus.br/geral/tribunal2/Trib_Sup/STF/CNJ/Res_185_13.html 
Damanpour, F., \&Gopalakrishnan, S. (1998). Theories of organizational structure and innovation adoption: The role of environmental change. Journal of Engineering and Technology Management, 15(1), 1-24.

Freitas, C. S. D., \& Medeiros, J. J. (2015). Organizational impacts of the electronic processing system of the Brazilian Superior Court of Justice. JournalofInformation Systems and Technology Management, 12(2), 317-332.

Fountain, J. (2005). Construindo um Estado Virtual: Tecnologia da informação e mudança institucional. Brasília: ENAP.

Hauknes, J. (1998). Services in innovation: Innovation in services [SI4S Synthesis Papers S1]. Oslo: STEP.

Halvorsen, T., Hauknes, J., Miles, I., \&Roste, R. (2005).On the differences between public and private sector innovation [Publin Report D9]. Oslo: NIFU STEP.

Koch, P., \&Hauknes, J. (2005). On Innovation in the Public Sector [Publin Report D20]. Oslo: NIFU STEP.

Lekhi, R. (2007). Public Service Innovation: A Research Report for The Work Foundation's Knowledge Economy Programme. London: Work Foundation.

Lima, C. M., \& Cruz, M. G. V. (2011, Setembro).O Conselho Nacional de Justiça e as reformas do poder judiciário: Aspectos da tecnologia da informação. Anais do XXXV Encontro ANPAD, Rio de Janeiro, RJ.

Miller, V. D., Johnson, J. R., \& Grau, J. G. (1994). Antecedents to willingness to participate in a planned organizational change.JournalofApplied Communication Research, 22, 59-80.

Organização de Cooperação e Desenvolvimento Econômico (2005). Manual de Oslo: Diretrizes para coleta e interpretação de dados sobre inovação (3a ed.). Paris: OECD Publishing.

Rafferty, A. E., Jimmieson, N. L., \&Armenakis, A. A. (2013). Change Readiness: A multilevel review. Journalof Management, 39(1), 110-135.

Renault, S. R. T. (2005). A reforma do Poder Judiciário sob a ótica do governo federal. Revista do Serviço Público, 58(2), 127-135.

Rodrigues, A., Assmar, E. M. L., \&Jablonski, B. (2009). Atitudes: Conceito e formação. In Rodrigues, A., Assmar, E. M. L., \&Jablonski, B. (Eds.). Psicologia Social (27a ed., pp. 81-112.). Rio de Janeiro: Vozes.

Rogers, E. M. (1983). Diffusion of Innovations. New York: Free Press.

Sadek, M. T. A. (2004). Poder judiciário: Perspectivas de reforma. Revista Opinião Pública, 10(1), 1-62.

Sampieri, R. H., Collado, C. F., \& Lucio, P. B. (2006). Metodologia de Pesquisa (3a ed.). São Paulo: McGraw Hill.

Shim, J. T., Sheu, T. S., Chen, H. G., Jiang, J. J., \& Klein, G. (2010).Coproduction in successful software development projects.Information and Software Technology, 52, 1062-1068.

Sousa, M. M, \& Guimarães, T. A. (2014). Inovação e desempenho na administração judicial: Desvendando lacunas conceituais e metodológicas. Revista de Administração e Inovação, 11(2), 321-344.

Sousa, M. M, \& Guimarães, T. A. (2017). The adoption of innovations in Brazilian labour courts from the perspective of judges and court managers. Revista de Administração, 52(1), 103-113.

Stumpf, J. C. (2009). Poder Judiciário: Morosidade e inovação. Porto Alegre: Tribunal de Justiça do Estado do Rio Grande do Sul.

Torfing, J. (2013). Collaborative innovation in the public sector. In Osborne, S. P., \& Brown, L. (Eds.). Handbook of innovation in public services.Cheltenham, UK - Northampton, MA, USA: Edward Edgar, 1-19.

Van de Ven, A. H., \& Sun, K. (2011). Breakdowns in Implementing models of organization change.

Academyof Management Perspectives, 25(3), 58-74. 
Vieira, J. L., \& Pinheiro I. A. (2008, Setembro). Contribuições do Conselho Nacional de Justiça para a gestão do poder judiciário. Anais do XXXII Encontro ANPAD (EnANPAD), Rio de Janeiro, RJ.

Submetido em: 10/12/2016

Aprovado em: 11/07/2017 